\title{
PABLO SEGUIDOR DEL JESÚS DE LA HISTORIA
}

\author{
Eduardo de la Serna \\ Quilmes (Buenos Aires) \\ edelaserna96@gmail.com
}

Resumen: Por más de un siglo se sostenía la idea de que Pablo, o bien ignoraba o no estaba interesado en aludir al Jesús histórico. Hoy esto es puesto en cuestión o incluso negado. En el presente artículo se pretenden mostrar elementos (dichos, temas, principios teológicos) que Pablo parece conocer provenientes de Jesús, aunque hacer mención de él no esté en el centro de su estrategia pastoral. Lo que Pablo conoce y señala de Jesús da fundamento a su cristología.

Palabras clave: Pablo. Jesús histórico. Kerigma. Cristología.

\section{Paul follower of the Historical Jesus}

Abstract: For more than a century was held the idea that Paul either ignored or was not interested in referring to the historical Jesus. Today this is questioned or even denied. In this article we try to show elements (sayings, themes, theological principles) that Paul seems to know coming from Jesus, although mentioning him is not at the center of his pastoral strategy. What Paul knows and points out of Jesus gives foundation to his Christology.

Key words: Paul. Historical Jesus. Kerygma. Christology.

Jesús, en su ministerio, tuvo seguidores. El motivo del seguimiento sin duda no era uniforme. Sin embargo, sean estas causas las que fueren, la cruz desarma todas estas razones (cf. Lc 24,21; Jn 21,3). Pero la experiencia de la resurrección reaviva las expectativas, aunque de un modo radicalmente nuevo. Una pregunta se impone: ¿quién era entonces? Es el surgimiento 
de la "cristología". Los discípulos continúan la predicación del Maestro, pero ahora incorporando a Jesús en ella. La resurrección aporta una mirada radicalmente nueva. ¿De dónde, sino de las Escrituras, se podrían afirmar cosas de Jesús? Jesús es "Cristo" por su muerte y resurrección (1 Cor 15,3), es "hecho Hijo" por la resurrección (Rom 1,4), es "Señor" porque "Dios lo exaltó" (Flp 2,9). La eficacia de la muerte "por nuestros pecados" (1 Cor $15,3)$, de su obediencia "hasta la muerte de cruz" (Flp 2,8) es importante en la predicación apostólica. Jesús había venido a anunciar que Dios está comenzando a reinar, permitiendo reunir a todas las ovejas perdidas del pueblo de Israel (Mt 10,6; 15,24) en el reconocimiento de todos como hermanos, particularmente de los rechazados: los publicanos y pecadores, los niños y los pobres, las mujeres y los impuros. La relativización de otros aspectos, a veces considerados centrales por muchos, tales como el templo, los sábados, las leyes alimentarias y ayunos, sin duda era también chocante para los "celosos" del pueblo. Así, la predicación de los seguidores de Jesús no invitaba a una buena "publicidad de la persona" del Maestro, incorporado en la predicación, para los sectores más fielmente religiosos de Israel.

\section{Pablo, perseguidor de los seguidores de Jesús}

La pregunta: “Entonces, ¿quién era?”, como reacción a partir de la crisis de la cruz, no es pregunta que Pablo se hiciera, puesto que no tenía esas expectativas previas que acompañaron a los primeros seguidores del Nazareno.

Pablo no conoce a Jesús en persona, pero ha oído hablar de él por la predicación de sus seguidores, y por eso "lo persigue". Pero la incorporación de Jesús a la predicación, y particularmente el sentido dado al escándalo de la cruz, provocan rechazo.

Los judíos no creyentes (en Cristo) consideraban que su predicación de un Mesías crucificado era un "escándalo" (1 Cor 1,23). A juicio de ellos, Dt 21,23 probaba que sobre un hombre crucificado pesaba la maldición de Dios (Gal 3,13) ${ }^{1}$.

Es el ser celoso lo que lleva a Pablo a la persecución de los seguidores de Jesús.

En los evangelios, los "celos" ( $z \bar{e} l o s)$ se encuentran solo una vez ("el celo de tu casa", Jn 2,17), en Hechos (4x: 5,17; 7,9; 13,45; 17,5) puede traducirse por "envidia", como también en Santiago (3x: 3,14.16; 4,2), "enojo" en Heb 10,27. Fuera de esto, los "celos" se encuentran 18x en Pablo. En oca-

1 Dunn, “El rostro humano de Dios", 194. 
siones también es "envidia" (Rom 13,13; 1 Cor 3,3; 2 Cor 12,20; Gal 5,20), en otras es un "deseo fuerte", una aspiración (1 Cor 12,31; 14,1.39), una "preocupación" (2 Cor 7,7.11; 11,2), "entusiasmo" (2 Cor 9,2), incluso puede ser un deseo no siempre bien orientado (Rom 10,2; Gal 4,17.18). En Flp 3,6, Pablo recuerda su "celo", que lo llevó a ser "perseguidor" 2 . Así se puede ser "celote" de dones, (1 Cor 14,12) o de las tradiciones (Gal 1,14; cf. Hch 22,3). La imagen que él tiene del grupo de Jesús es la que lo lleva a perseguirlo, seguramente porque ve "peligrar" las tradiciones de sus antepasados.

Pero, a partir de un momento concreto, Pablo tiene una experiencia del Resucitado a la que ha llamado "visión" (eóraka, perfecto: 1 Cor 9,1; ofthê, aoristo: 15,8), la cual no sabemos con exactitud en qué consistió. Su efecto es que la experimentó como una "revelación" (Gal 1,16): lo "escondido" en la cruz se le reveló por medio de su espíritu (1 Cor 2,10); "antes de que llegara la fe estábamos encerrados bajo la vigilancia de la Ley, en espera de la fe que debía manifestarse" (Gal 3,23).

\section{El conocimiento de Cristo}

Pablo hace referencia al pasado diciendo: "Si conocimos a Cristo", pero esto parece referirse a este en cuanto predicado por los seguidores; y de ese "conocimiento" (en tiempo perfecto) afirma:

De modo que nosotros de ahora en adelante no consideramos [oídamen, tiempo perfecto] a nadie con criterios humanos [kata sarka]; y si un tiempo conocimos [egnôkamen] a Cristo con criterios humanos [kata sarka], ahora ya no lo conocemos [ginôskomen, tiempo presente] $(2$ Cor 5,16$)$.

Pablo alude frecuentemente en sus escritos a los "modos humanos" (kata sarka) (16x). Con frecuencia se refiere con esto a algo "natural" (hijo "según la carne" se refiere a la naturaleza humana, Rom 1,3; véase 4,1; 9,3.5; 1 Cor 1,26; 10,18; Gal 4,23.29; 2 Cor 10,2). En Rom 8,4.5 se contrapone a lo "espiritual" (kata pneuma; véase 8,13). En 2 Cor 1,17, Pablo les indica a los corintios que su anuncio -finalmente no concretado- de visitar Corinto no estuvo motivado por ligereza, por "proyectos kata sarka", sino movido por Dios mismo. En 2 Cor 10,3 afirma que "no combate kata sarka" y que muchos se jactan kata sarka $(11,18)$ mientras que él lo hará, pero jactándose de su "debilidad" $(11,30)$. Pablo contrasta, entonces, un

2 En de la Serna, “¿Pablo el precursor?”, 161-180, hemos propuesto que Pablo ve su ministerio como una continuidad con la persona de Elías, el esperado. Los “celos", sin duda, son una característica que acompaña a ambos. 
doble modo de "conocimiento", de un tiempo pasado ("conocimos", tiempo perfecto) contrastado con un doble "ahora" (ya no "consideramos" [perfecto], ya "conocemos" [presente]). El conocimiento según la carne era de un Cristo predicado que resultaba intolerable para los celos paulinos; pero "ahora conocemos" de un modo nuevo. Pablo vuelve a referirse al conocimiento actual en Gal 4,9: "Ahora conocemos a Dios, o, mejor dicho, él nos conoce", por lo que no tiene sentido alguno "volver" al pasado, a los "elementos", algo que era propio de los "menores de edad" (nēpios, 4,3). El tiempo escatológico del Espíritu lleva a un nuevo modo de conocimiento, así conocemos ahora a Cristo, "tenemos su mente" (1 Cor 2,16).

Sin duda, debemos señalar entonces que, cuando Pablo hace referencia a su conocimiento de Jesucristo, se refiere expresamente a dos modos de conocimiento, el primitivo, kata sarka, ya pasado, y el actual (nûn), espiritual, del Glorificado.

\section{Pablo y Jesús de Nazaret}

Ahora bien, ¿podemos señalar entonces que Pablo conoce algo de Jesús de Nazaret? Y, si lo conoce, ¿de dónde recibe lo que conoce? ¿De Damasco? ¿De Arabia? ¿De Pedro? ¿De Antioquía? ¿De Bernabé? Él no lo dice, por lo que no es fácil concluirlo.

Sabemos que Pablo recurre a elementos prepaulinos en la predicación o en sus escritos (1 Cor 5,10-11; 6,9-10; 2 Cor 12,20-21; Gal 5,19-23; Rom 1,19-31; 13,13), en credos ( 1 Te 1,9-10; 1 Cor 8,6; 15,3b-5; Rom 1,3b-4a; 10,9; Flp 2,6-11) y en lo sacramental (1 Cor 1,30; 6,11; 2 Cor 1,21-22; Gal 3,26-28; Rom 3,25; 4,25; 6,3-4 y 1 Cor 11,23b-25; 16,22). En más de una ocasión Pablo remite a la "tradición" como la fuente, expresada con los verbos "recibí" / "transmitî" (paralambánō / paradídōmi) (1 Cor $11,23 ; 15,3)$, pero nuevamente toca saber de dónde "recibe" Pablo aquello que "transmite". Sin duda, la vida de Pablo en diferentes comunidades y con diferentes personajes hacen razonable entender que Pablo recibe de muchos de ellos diferentes elementos más o menos tradicionales.

Con mucha seriedad, V. P. Furnish muestra las diferentes perspectivas históricas de los más variados autores, desde Ferdinand Christian Baur (1831) hasta Rudolf Bultmann (1929)³, presentando la relación entre Jesús y Pablo, donde finalmente Jesús es convertido en kerygma del cual Pablo es predicador:

3 Furnish, “The Jesus-Paul Debate", 17-50. 
Por tanto, no se debe intentar ir más allá del kerygma, usándolo como una "fuente" para reconstruir un "Jesús histórico" [historische] con una "autoconciencia mesiánica", su "interioridad" o su "heroísmo". Eso sería precisamente el Christos kata sarka que ya no existe. No es el Jesús histórico [historische], sino Jesucristo, el proclamado, el que es Señor ${ }^{4}$.

Durante mucho tiempo, la exégesis del siglo xx tenía en cuenta este criterio indiscutido: Pablo, o bien no conoce o bien no está interesado en el Jesús histórico, sino en el glorificado, en el predicado (kerygma) $)^{5}$. Pero -y lo sigue diciendo Furnish- esto no era grato a los oídos más conservadores:

La costumbre de los intérpretes conservadores (por ejemplo, Paret, Vischer, Kittel, Machen, Turlington, pero también Kümmel) ha sido sostener que Pablo guarda silencio sobre el Jesús histórico porque presupone el conocimiento de sus lectores sobre la vida y la enseñanza de Jesús. Este conocimiento, se afirma, les fue transmitido en la predicación misionera del apóstol 6 .

Esto lo siguen manteniendo todavía algunos autores contemporáneos:

Puesto que las cartas paulinas no reflejan el "primer anuncio" misionero, sino que son reacción catequística a partir de él, queda la pregunta: ¿hablaba Pablo de Jesús al predicar?

- "La historia de Jesús Cristo debe presuponerse como el contenido de la predicación oral de Pablo" (Eckart Reinmuth) 7 .

- "Llevó a cabo el anuncio inicial en el que tenía necesariamente que hablar de Jesús de Nazaret y ofrecer informaciones básicas sobre su persona y vida terrena" (Pastor-Ramos) ${ }^{8}$.

Correctamente, Heitmüller critica esto afirmando que es mera conjetura ${ }^{9}$. Y concluye Furnish destacando que

uno debe preguntarse si no es cierto que, aunque las cartas en general presuponen la predicación misionera del apóstol, de todos modos proporcionan algunas pistas sobre su probable contenido. Uno piensa inmediatamente en 1 Corintios 2.1-2 ("Cuando fui a ustedes, hermanos, no fui a

4 “Die Bedeutung des geschichtlichen Jesus fur die Theologie des Paulus", en TBI 8 (1929) 137-151, luego en Glauben und Verstehen 1, Tubingen 1933, 188-213 (citado en "The Jesus-Paul Debate", 208).

5 Sobre esto hemos trabajado en DE LA SeRna, "El kerigma de Pablo".

6 Furnish, "The Jesus-Paul Debate", 45.

7 Citado en Schnelle, Apostle Paul, 107, n. 21.

8 Pastor-Ramos, Para mí, vivir es Cristo, 93.

9 Furnish, "The Jesus-Paul Debate", 45. 
proclamarles el misterio de Dios en palabras elevadas o sabiduría. Pues decidí no saber nada entre ustedes, excepto Jesucristo, y él crucificado") y 1 Tesalonicenses 1,9-10 (donde Pablo se refiere a su visita inicial y “cómo [los tesalonicenses] se volvieron a Dios de los ídolos, para servir a un Dios vivo y verdadero, y para esperar a su Hijo del cielo, a quien él levantó de los muertos, Jesús, que nos libera de la ira venidera"). No hay nada en estos resúmenes de su predicación misionera en Corinto y Tesalónica para apoyar la conjetura de que la narración de la vida terrena de Jesús o la instrucción de sus dichos fue la parte central o incluso una parte esencial de ella ${ }^{10}$.

Pero esto no niega que Pablo conozca algo del "Jesús histórico".

Es incluso probable que Pablo conociera dichos de Jesús y estuviera más informado del Jesús histórico de lo que indica en sus cartas ${ }^{11}$. Sin embargo, es de destacar que el apóstol hace un uso muy limitado de este posible conocimiento y no lo integra en la línea de argumentación seguida en sus $\operatorname{cartas}^{12}$.

\section{Jesús en las cartas paulinas}

Sociológicamente, Pablo es miembro de un "culto" [= movimiento] más que de una "secta" [= grupo cerrado ${ }^{13}$, y por eso no es fundamental para ellos lo "histórico"; por ejemplo, todo indica que conoce el marco dramático que incluye la cruz (cualquier habitante del Imperio romano podía conocerlo), pero solo alude a ella sin referirse a datos complementarios, como las torturas, las burlas, el deshonor, etc. La preocupación por la historia (pasado) en un colectivo es importante cuando empiezan a morir los testigos (62-68 d. C.), mientras que, en Pablo, lo que cuenta es el futuro, las consecuencias de lo que se "acaba" de vivir, la "venida" de Jesús. Los discursos en Hechos justificando la apertura a los paganos (como también lo hará Pablo) tampoco aluden a Jesús (quien, además, seguramente no lo previó). De forma esquemática, y algo sintéticamente, podemos decir que a Pablo le interesa más el "Jesús que viene" que el "Jesús que vino".

10 Ib., 46.

11 “Podemos deducir razonablemente que Pablo conocía de la vida del Jesús terreno mucho más de lo que aparece en sus cartas", PASTOR-RAMOS, Para mí, vivir es Cristo, 93-94.

12 Schnelle, Apostle Paul, 105.

13 Cf. MASON - EsLer, “Judean and Christ-Follower Identities”. La distinción sociológica la presenta WHITE, "Shifting Sectarian Boundaries", 15: "In the roman World: Sects or Cults?": "One problem is a matter of technical vocabulary, as the term typically applied to millenarian movements is 'cult' not 'sect' (p. 16). 
Sabemos que las cartas paulinas son cartas de "circunstancia", son escritas "en contexto", por lo que hemos de tener presente que hay en ellas muchos silencios sobre muchos temas que no implican que Pablo los desconozca o no le interesen, sino que el motivo de la carta o del tema no hacen necesario o pertinente aludir a ellos.

Resulta muy sano, a mi modo de ver, recordar que las cartas de Pablo no son sino una parte (quizá no la más importante) de su proyecto mesiánico; Pablo las acompañaba de su presencia personal, de los colaboradores enviados, del conocimiento de primera mano de la situación de sus destinatarios, de la estrategia de los líderes locales, etc. [...] No debemos absolutizar el texto para comprender el proyecto y la misión de Pablo; es fundamental referirlo a su contexto y a su vida ${ }^{14}$.

En uno de los pocos textos (apologéticos, a raíz de la circunstancia vivida en la comunidad) en los que Pablo debe hablar de él kata sarka, su referencia explícita es al Resucitado, que es el Crucificado (Gal 1,13-16).

Esta conversión [sic] transforma por entero su existencia, no solo sus acciones y también su cuerpo físico, en un patrón cruciforme (cf. 6,17). Pablo es "co-crucificado" con el Mesías, quien entonces permanece y habilita sus acciones: "Ya no soy yo quien vive, sino Cristo que vive en mí" $(2,20)$. Pero diciendo que el Hijo de Dios se reveló "en" él, Pablo interpreta su propia conversión [sic] y llamada en el momento en que deviene una representación y continuación de la divina revelación escatológica de Jesucristo al mundo. Pablo mismo deviene un apocalipsis ${ }^{15}$.

\section{O para repetirlo con un autor reciente:}

Porque a él le fue revelado que la pasión es la expresión perfecta del amor de Cristo por su Padre y por la humanidad, al mismo tiempo que la naturaleza paradójica de lo todopoderoso del Dios de Jesucristo; Pablo decidirá no buscar más que a Jesucristo crucificado para ser crucificado con él: "Yo he decidido no saber entre ustedes sino a Jesucristo, y Jesucristo crucificado" (1 Cor 2,2) ${ }^{16}$.

Pero, para ser precisos y para preguntarnos por dichos o hechos del Jesús histórico y su posible conocimiento o influencia en el Pablo histórico, por otra parte sería necesario una seria investigación sobre los dichos y hechos que los evangelios nos narran y reconocer cuáles pertenecen (o no) al Jesús histórico. Una lectura excesivamente "lineal" no debería ser valorada con seriedad. Hasta podría darse el caso -hipotéticamente hablandode que algún evangelio ponga en boca de Jesús algo que es originalmente paulino; al menos cronológicamente es una posibilidad.

14 GIL ArbIol, Qué se sabe de... Pablo en el naciente cristianismo, 27.

15 Williams, “Disjunction in Paul”, 75.

16 Debergé, Je sais en qui jáai mis ma foi, 22. 
Es interesante tener en cuenta que el florecimiento de la búsqueda de Jesús que se ha llamado "tercera búsqueda" ${ }^{17}$ también ha llevado a profundizar el conocimiento de los "orígenes cristianos" ${ }^{18}$ y -por tanto- del Pablo histórico. Ambos estudios se interrelacionan, sin duda.

\section{Citas explícitas}

Si nos dejamos guiar por el mismo Pablo, hay tres textos en los que expresamente afirma remitir a Jesús; los tres se encuentran -icuriosamente?- en 1 Corintios:

- 9,14: "El Señor ha ordenado que los que predican el evangelio vivan del evangelio": se refiere a la ayuda a los misioneros (Mt 10,10 / Lc 10,7). Es interesante notar que Pablo se siente con libertad de corregir algo el dicho o su aplicación; de hecho, él trabaja ${ }^{19}$.

- 7,10: "A los casados les ordeno, no yo, sino el Señor": se refiere a la prohibición del divorcio (Lc 16,18; Mc 10,2-12) - También se ha de notar que Pablo se siente con libertad de corregir algo el dicho y ve razonable la separación de aquellos matrimonios en los que una parte se ha convertido mientras la otra no lo ha hecho ${ }^{20}$.

- 11,23-25: "Yo recibí [paralambanō] del Señor lo que les he transmitido [paradídōmi]: que el Señor Jesús, la noche en que fue entregado [paradídōmi], tomó pan y, después de dar gracias, lo partió y dijo: 'Este es mi cuerpo, que se da por ustedes; hagan esto en memoria mía'. Asimismo, también la copa después de cenar, diciendo: 'Esta copa es la nueva alianza en mi sangre. Cuantas veces la beban, háganlo en memoria mía"'. Remite a la institución de la cena (Mc 14,22-25 / Lc 22,14-20). "La noche en que fue entregado" (imperfecto, voz pasiva), ¿por Judas? (cf.Lc 22,4.6.21.22.48); pero en Pablo el verbo se aplica "a la muerte" (cf. Rom 4,25, aoristo); Dios "lo entregó" (Rom 8,32, aoristo), "se entregó" (Gal 2,20, aoristo), "nos vemos continuamente entregados [pasivo presente] a la muerte por causa de Jesús" (2 Cor 4,11). No es evidente el sujeto de la entrega.

17 Entiendo que, con justicia, la referencia a la actual búsqueda presentada como "tercera" es cuestionada por AguiRre, La memoria de Jesús y los cristianismos de los orígenes, 81-89.

18 Sobre esto hemos trabajado en DE LA SeRnA, De Jesús a la Gran Iglesia.

19 De la Serna, “La justificación por la fe”.

20 Una mirada diferente y sugerente de "los demás" en Ferrer, Parejas y sexualidad en la comunidad de Corinto. 
Es de señalar que en los tres casos en los que expresamente Pablo alude a Jesús utiliza el término "Señor" (kyrios). Con lo que habría que relativizar lo dicho por Sánchez Bosch: "Queda claro que el simple nombre 'Jesús' está casi siempre asociado a algún recuerdo del Cristo terreno" 21. El término lo encontramos solo 14 veces sin predicado (= Señor, Cristo): Rom 3,26; 8,11; 1 Cor 12,3; 2 Cor 4,5.10(2x).11(2x).14; 11,4; Gal 6,17; Flp 2,10; 1 Te 4,14 (cf. 1 Te 1,10). Por otra parte, se ha de notar que, en los tres casos citados, Pablo recurre a Jesús como "argumento de autoridad" para señalar lo que "se ha de hacer".

\section{Pablo y otras referencias a Jesús}

Sin embargo, se ha de señalar que la referencia al acontecimiento histórico de la cruz parece, en Pablo, más destacado por sus "efectos" ("por nuestros pecados", 1 Cor 15,3) que para hablar del hecho histórico (sin duda alguna, algo conocido por el apóstol).

Pablo afirma que el conocimiento del acontecimiento escatológico de la muerte de Jesús supera el de los demás acontecimientos de su vida y se erige en su criterio hermenéutico. Esto es lo que le permite desarrollar la cristología y la eclesiología más allá de la cristología implícita; Dios había hablado en la cruz de Jesús más que en todos los dichos y hechos de su vida $^{22}$.

Hay en sus cartas referencia al reino de Dios (Rom 14,17; 1 Cor 4,$20 ; 15,50 ; 1$ Te 2,12, aunque este en Pablo es solo escatológico) y su tiempo de cumplimiento ( $\mathrm{Gal} 4,4)$, el cumplimiento de las Escrituras (Gal 5,14; Mc 14,49; Mt 1,22 pass., cf. 2 Cor 6,2).

También se suele señalar que Jesús es "humano" [sic $]^{23}$ (cf. Rom 5,15; 1 Cor 15,21); judío (Gal 4,4; 3,16), de la "familia de David" (Rom 1,3), que tenía hermanos (1 Cor 9,5), uno de los cuales era Santiago (Gal 1,19). Conoce a los doce, y especialmente a Pedro (1 Cor 9,5; 15,5; Gal 2,7-8) ${ }^{24}$. Desarrolló su ministerio entre judíos (Rom 15,8). Es paciente y humilde (2 Cor 10,1 / Mt 11,29), resistente y obediente (Rom 5,19; obviamente

21 Sánchez Bosch, Maestro de los pueblos, 97.

22 GIL Arbiol, “La contribución de Pablo al conocimiento de Jesús”, 422.

23 Pastor-Ramos, Para mí, vivir es Cristo, 90.

${ }^{24}$ Sobre el encuentro de Pablo con Pedro hemos escrito en De La Serna, "La figura de Pedro en los escritos de Pablo"; en pp. 152-155 nos referimos a la posible información que Pedro puede haber aportado a Pablo, expresada en el verbo historēsai. 
no se refiere al Exaltado), es la "Pascua" y crucificado ( 1 Cor 5,7; 2,8; Gal 3,13), "muerto y sepultado" (1 Cor 15,4). Los (jefes) judíos participan en su muerte (1 Te 2,15), y especialmente los "jefes de este mundo" (1 Cor 2,8), en Gal 6,17 habla de stigmata, y en 2 Cor 4,10, de la nekrôsis (cf. 2 Cor 1,5; Flp 3,10).

Se dirige a Dios como abbá (Mc 14,36; Gal 4,6; Rom 8,15); el “inclasificable" Dios de misericordia es coherente en Jesús y en Pablo, y esto implica consecuencias para los excluidos.

Afirma que Jesús "volverá" pronto (1 Te 4,15, y lo dice "como palabra del Señor"; Mc 13,30), compara el "día del Señor" con la venida de un ladrón (1 Te 5,2 / Mt 24,43).

\section{Otros elementos aproximativos}

Jesús y Pablo hacen referencia a la justificación por la gracia, no por las obras (como se ve en las parábolas del fariseo y el publicano, del hijo perdido y encontrado, de la llegada de viñadores a trabajar en diferentes horas (Lc 18,9-14; 15,11-32; Mt 20,1-15); los viñadores homicidas (Mc 12,1-11; cf. Gal 4,4; Rom 8,3); "entrada de los paganos" (Rom 9-11); Jesús vino "siendo nosotros pecadores" (Rom 3,22-25; 5,8); Jesús como médico a los enfermos, etc.

Presenta la centralidad del amor (Gal 6,2) "al prójimo" (Rom 13,810), que es "el" fruto del Espíritu (Gal 5,22). La centralidad del amor es evidente en 1 Cor 13 , y es superior a una fe que mueve montañas $(13,2$, cf. Mt 17,20).

Si bien, como reconoce con justicia Elisabeth Schüssler Fiorenza, no puede sostenerse que "todo el judaísmo" rechazaba a las mujeres ${ }^{25}, \mathrm{y}$ que Jesús establece una radical novedad, sí se ha de señalar que Jesús las incorpora a su grupo cercano y también Pablo reconoce su importancia (Rom 16). Del mismo modo se señala el cuidado de los débiles: 1 Cor 8,4. La centralidad de los pobres para Jesús también se nota en Pablo (cf. 1 Cor 11,17-34; la colecta para los pobres de Jerusalén, cf. 2 Cor 8-9), aunque esto -como lo anterior, sobre las mujeres- no necesariamente ha de deberse a un conocimiento de las tradiciones jesuánicas, sino simplemente a ser ambos buenos judíos.

25 Schüssler Fiorenza, Jesus, Miriam's Child, Sophia's Prophet, “produce por la izquierda un antijudaísmo cristiano y por la derecha un masculinismo divino en cristología" (p. 89). Ya lo había señalado en su obra En memoria de ella. 
A continuación, se pueden ver algunos textos que parecen tener influencia del Nazareno en los escritos paulinos:

\begin{tabular}{|l|l|}
\hline $\begin{array}{l}\text { Buena es la sal; mas, si la sal se vuelve } \\
\text { insípida, ¿con qué la sazonarán? Tengan sal } \\
\text { en ustedes y tengan paz unos con otros (Mc } \\
9,50) .\end{array}$ & $\begin{array}{l}\text { Ténganlos en la mayor estima con amor por } \\
\text { su labor. Vivan en paz unos con otros (1 Ts } \\
5,13) .\end{array}$ \\
\hline $\begin{array}{l}\text { Ustedes han oído que se dijo: "Ojo por ojo, } \\
\text { diente por diente" (Mt 5,38-48). }\end{array}$ & $\begin{array}{l}\text { Miren que nadie devuelva a otro mal por } \\
\text { mal; antes bien, procuren siempre el bien } \\
\text { mutuo y el de todos (1 Tes 5,15). }\end{array}$ \\
\hline $\begin{array}{l}\text { Amen a sus enemigos, traten bien a los que } \\
\text { los odian; bendigan a los que los maldicen, } \\
\text { recen por los que los injurian (Lc 6,27-28). }\end{array}$ & $\begin{array}{l}\text { Bendigan a los que los persiguen, bendigan } \\
\text { y naldigan nunca [...] A nadie devuelvan } \\
\text { mal por mal, procuren hacer el bien delante } \\
\text { de todos los hombres (Rom 12,14-17). }\end{array}$ \\
\hline $\begin{array}{l}\text { Jesús les dijo: "Lo del César, devuélvanselo } \\
\text { al César, y lo de Dios, a Dios" (Mc 12,17). }\end{array}$ & $\begin{array}{l}\text { Den a cada uno lo debido: al que se debe } \\
\text { impuestos, impuestos; al que se debe } \\
\text { contribución, contribución; al que respeto, } \\
\text { respeto; al que honor, honor (Rom 13,7). }\end{array}$ \\
\hline $\begin{array}{l}\text { Nada hay fuera del hombre que, entrando en } \\
\text { él, pueda contaminarle, sino lo que sale del } \\
\text { hombre, eso es lo que contamina al hombre } \\
\text { (Mc 7,15). }\end{array}$ & $\begin{array}{l}\text { Bien sé, y estoy persuadido de ello en el } \\
\text { Señor Jesús, que nada hay de suyo impuro; } \\
\text { a no ser para el que juzga que algo es } \\
\text { impuro, para ese sí lo hay (Rom 14,14). }\end{array}$ \\
\hline $\begin{array}{l}\text { Que la palabra de ustedes sea sí, sí; no, no. } \\
\text { Lo que se añada luego procede del Maligno } \\
\text { Mt 5,37). }\end{array}$ & $\begin{array}{l}\text { Dios me es testigo de que, cuando me dirijo } \\
\text { a ustedes, no confundo el sí y el no; porque } \\
\text { el Hijo de Dios, Jesucristo, el que nosotros } \\
\text { con Silvano y Timoteo les predicamos, no } \\
\text { fue un sí y un no, ya que en él se cumplió el } \\
\text { sí (2 Cor 1,18-19). }\end{array}$ \\
\hline
\end{tabular}

Sin duda alguna, el tema principal del Jesús histórico al que Pablo alude con frecuencia es la cruz, la cual representa la expresión de una "abreviación narrativa" del Jesús histórico:

Siempre mantiene su referencia a un lugar histórico particular y a la muerte espantosa que allí ocurrió, incluso en textos donde Pablo lo integra en narrativas mitológicas [...] allí donde aparece la cruz en los escritos de Pablo, esta contiene la totalidad de la historia de Jesucristo ${ }^{26}$.

"Porque tampoco Cristo buscó su propia satisfacción, sino que, como está escrito: "Cayeron sobre mí los ultrajes de los que te agravian'" (Rom 15,3; cf. Mc 15,28.31).

26 Schnelle, Apostle Paul, 106. 
"Jesús fue el hombre cuya muerte refleja mejor que ningún otro evento histórico quién y cómo es Dios" 27.

Un tema en debate es notar que Pablo habla de "la fe de Jesús" (Gal 2,16.20; 3,22; Rom 3,22.26; Flp 3,9), la cual puede entenderse objetiva o subjetivamente. Sin duda que, si estuviera hablando de la fe/fidelidad "que tuvo" Jesús, estaría refiriéndose al Jesús histórico. Y no parece improbable que esté aludiendo a eso ${ }^{28}$.

\section{Aportes paulinos a la imagen de Jesús}

Esquemáticamente podemos preguntarnos cómo influye Pablo en la conformación de una "imagen de Jesús" en el cristianismo primitivo (a su vez asumiendo lo que ha recibido):

- Como "Adán", Jesús es "humano", no hay ruptura entre el Resucitado y el Crucificado.

- Es "Señor" (marana-tha) por no haber repetido el "modelo Adán" de aferrarse a ser imagen de Dios haciéndose "esclavo", por eso "Dios lo exaltó". "Jesús no ha sido siempre Señor, sino que ha llegado a serlo después de haber elegido hacerse "esclavo', es decir, hombre mortal entre los mortales" 29 .

- Es "hijo" del abbá por la resurrección (no debemos leerlo en clave joánica). Jesús, "enviado" como los profetas o como Moisés, obediente y confiado, reproduce la imagen de Dios (quien ve al Crucificado ve cómo es Dios).

- Por eso Jesús es "Cristo", uniendo su vida histórica con su confesión como Exaltado.

El "teólogo en epístola" -como ha llamado a Pablo Giuseppe Barbaglio- que escribe para dar respuestas a temas precisos que se le plantean en circunstancias y ocasiones y comunidades precisas, no parece que necesite recurrir al "Jesús histórico" para enfrentar las situaciones; pero eso no implica que su predicación no esté "arraigada" en el Jesús que el movimiento de los "seguidores del camino" reconoce y confiesa.

\footnotetext{
27 GIL ArBIOL, “La contribución de Pablo”, 431.

28 Cf. de la Serna, “La fe en los escritos de Pablo”, espec. 89-91.

29 Barbaglio, Jesús de Nazaret y Pablo de Tarso, 245.
} 


\section{Bibliografía}

Aguirre, R., La memoria de Jesús y los cristianismos de los orígenes, Estella 2015.

Barbaglio, G., Jesús de Nazaret y Pablo de Tarso. Confrontación histórica, Buenos Aires 2008.

Bultmann, R., "La signification du Jésus historique pour la théologie de Paul" (1929), en Foi et compréhension I. L'historicité de l'homme et de la révélation. Paris 1970, 211-239.

Debergé, P., Je sais en qui j'ai mis ma foi. Perpignan 2013.

DunN, J. D. G., "El rostro humano de Dios; Dios y la cristología del Nuevo Testamento", en C. Bernabé (ed.), Los rostros de Dios. Imágenes y experiencias de lo divino en la Biblia (Asociación Bíblica Española 62). III Congreso Bíblico Internacional de la ABE (Sevilla, 3-5 septiembre 2012), Estella 2013, 183-196.

Furnish, V. P., "The Jesus-Paul Debate: from Baur to Bultmann", en A. J. M. Wedderburn (ed.), Paul and Jesus. Collected Essays, London New York 2004, 17-50; artículo originalmente aparecido en Bulletin of the John Rylands Library 47 (1964-1965) 342-81.

Gil Arbiol, C., "La contribución de Pablo al conocimiento de Jesús", en P. Martinelli - L. Bianchi (eds.), In caritate veritas. Scritti in memoria di Luigi Padovese, vescovo cappucchino, vicario apostolico dell'Anatolia, Bologna 2011, 417-431.

-, Qué se sabe de... Pablo en el naciente cristianismo, Estella 2015.

Ferrer, P. M., Parejas y sexualidad en la comunidad de Corinto, Buenos Aires 2010.

Mason, S. - Esler, Ph. F., "Judean and Christ-Follower Identities; Grounds for a Distinction", NTS 63 (2017) 493-515.

Pastor-Ramos, F., Para mí, vivir es Cristo. Teología de san Pablo. Persona, pensamiento, experiencia, anuncio, Estella 2010.

SÁnchez Bosch, J., Maestro de los pueblos. Una teología de Pablo, el apóstol, Estella 2007.

Schnelle, U., Apostle Paul. His Life and Theology, Grand Rapids, Mi 2005.

Schüssler Fiorenza, E., En memoria de ella, Bilbao 1989.

-, Jesus, Miriam's Child, Sophia's Prophet. Critical Issues in Feminist Christology, New York 1994.

Serna, E. DE la, De Jesús a la Gran Iglesia. El nacimiento del cristianismo, Buenos Aires ${ }^{2} 2014$.

-, "La fe en los escritos de Pablo", Atualidade Teologica (P.U.C. Rio de Janeiro) XVII/43 (2013) 70-100. 
-, "La figura de Pedro en los escritos de Pablo", RevistB 70 (2008) 133171.

-, "El kerigma de Pablo. Una mirada al ministerio paulino", Theologica Xaveriana, año $61 \mathrm{~N}^{\circ} 172$ (2011) 509-536.

-, "La justificación por la fe. Una mirada teológica del trabajo paulino", RevistB 68 (2006) 101-115.

Thiselton, A. C., The Living Paul. An Introduction to the apostle's Life and Thought, Downers Grove, IL 2010.

Wedderburn, A. J. M. (ed.), Paul and Jesus. Collected Essays, New York - London 1989.

White, L. M., "Shifting Sectarian Boundaries in Early Christianity", $B u$ lletin of the John Rylands University Library of Manchester 70 (1988) 7-24.

Williams, L. A., "Disjunction in Paul: Apocalyptic of Christophanic? Comparing the Apocalypse of Weeks with Galatians", NTS 64 (2018) 64-80.

[recibido: 23/07/18 - aceptado: 7/10/18] 